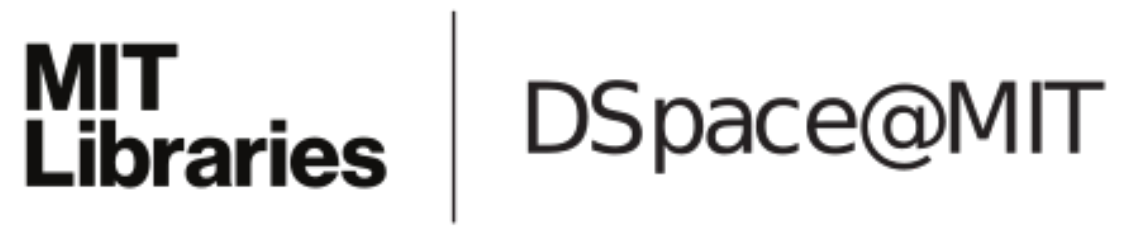

\author{
MIT Open Access Articles
}

Modeling of crack initiation, propagation and coalescence in rocks

The MIT Faculty has made this article openly available. Please share how this access benefits you. Your story matters.

Citation: Gonçalves da Silva, Bruno, and Herbert H. Einstein. "Modeling of Crack Initiation, Propagation and Coalescence in Rocks." International Journal of Fracture 182.2 (2013): 167-186.

As Published: http://dx.doi.org/10.1007/s10704-013-9866-8

Publisher: Springer Netherlands

Persistent URL: http://hdl.handle.net/1721.1/103151

Version: Author's final manuscript: final author's manuscript post peer review, without publisher's formatting or copy editing

Terms of use: Creative Commons Attribution-Noncommercial-Share Alike 


\title{
Modeling of Crack Initiation, Propagation and Coalescence in Rocks
}

\author{
Bruno Gonçalves da Silva \\ Massachusetts Institute of Technology \\ Department of Civil and Environmental Engineering \\ 77 Massachusetts Avenue, Room 1-343A, Cambridge, MA 02139, USA \\ E-mail: bmgsilva@mit.edu
}

\author{
Herbert H. Einstein \\ Massachusetts Institute of Technology \\ Department of Civil and Environmental Engineering \\ 77 Massachusetts Avenue, Room 1-342, Cambridge, MA 02139, USA \\ E-mail: einstein@mit.edu
}

\begin{abstract}
One of the most successful criteria proposed so far to describe the initiation and propagation of cracks under quasi-static loading in rock-like materials is a stress-based criterion developed by Bobet (1997) which is embedded in FROCK, a Displacement Discontinuity code that was developed by the rock mechanics group at MIT. Even though the predictions obtained with this criterion generally correspond to the experimental results, there are cases in which the quasi-static crack propagation results obtained with FROCK are not satisfactory.

For this reason, a qualitative study using the Finite Element code, ABAQUS, was conducted to analyze stress-, strain- and energy-based criteria used for modeling crack development. Based on the ABAQUS relative quantitative analysis, it was found that the strain- and stress-based criteria may be more appropriate than the energy-based criterion to model quasi-static crack development. Thus, a strain-based and a normal stress-dependent criterion were implemented in FROCK. The cracking patterns obtained with these proposed criteria were compared with those obtained using Bobet's original stress-based criterion and with experimental observations made in molded gypsum specimens. The proposed strain-based criterion implemented in FROCK appeared to yield better results than Bobet's stress-based criterion. The influence of the friction angle $(\varphi)$ on the cracking patterns was studied with the proposed normal stress-dependent criterion and showed that friction angles closer to $0^{\circ}$ yielded the best results, which may indicate that, at least for the microscale, the critical shear stress at which rock fails does not depend upon the normal stresses applied.
\end{abstract}

Keywords: crack propagation, modeling, boundary element method, finite element method, rock fracturing, crack initiation and propagation criterion 


\section{Introduction}

The study of crack initiation and -propagation is important for the understanding of rock mass behavior which, in turn, affects rock engineering applications, such as tunnels, foundations and slopes, as well as hydro-carbon and geothermal energy extraction. Cracking mechanisms can be studied experimentally in the laboratory or in the field, or numerically.

From the early $20^{\text {th }}$ century, many researchers developed criteria to describe the initiation, propagation and coalescence of cracks in brittle materials. Specifically, several crack initiation and propagation criteria based on the stress-, strain- and energy fields around a flaw tip have been developed and implemented, for instance, in Boundary Element (BE) and Finite Element (FE) codes (Erdogan and Sih 1963; Rice 1968; Sih 1974; Ingraffea and Heuze 1980; Chan 1986; Reyes 1991; Shen and Stephansson 1993; Bobet 1997 and 2000; Vásárhelyi and Bobet 2000; Isaksson and Ståhle 2002). In recent years, models such as hybrid experimental-numerical methods (Kobayashi, 1999, Yu and Kobayashi, 1994, Guo and Kobayashi, 1995), Extended Finite Element models (XFEM) with cohesive zone (Fagerström and Larsson, 2008, Xu and Yuan, 2011) and with porder spectral elements (Liu et al., 2011), peridynamics (Agwai et al. 2011 and Silling and Askari, 2005) have been used to simulate quasi-static and dynamic crack propagation problems. While these new methodologies have been very successful in predicting crack opening and even branching in mode I loading (Agwai et al. 2011), they have had more difficulty to accurately model Mode II or mixed Mode I/II fracture. Furthermore, even though XFEM models do not require remeshing, which was one of the major drawbacks of the conventional Finite Element models, they require very fine meshes to describe the analyzed body or, at least, the region where the crack is expected to grow. Because of this, the results obtained with XFEM models are usually significantly mesh-dependent (Agwai et al. 2011).

This paper specifically looks into the initiation, propagation and coalescence of cracks associated with double-flaw geometries (Reyes 1991; Bobet and Einstein 1998a, b; Martinez 1999; Wong 2008; Miller 2008) as shown in Fig. 1. In this study, the term flaw is used to describe artificially-created cracks induced in the rock specimen before it is uniaxially loaded. 
Starting with Chan (1986), the MIT rock mechanics group has been developing FROCK, a Displacement Discontinuity code (a type of Boundary Element model) which currently uses the stress-based criterion proposed by Bobet (1997) to model the cracking processes in rock-like materials. This code simulates the crack propagation resulting from quasi-static loading as a quasi-static-process i.e. dynamic effects are not taken into consideration. This assumption is valid, since the loading is applied at a very slow rate in the experiments performed by the MIT rock mechanics group. Consequently, for quasi-static loading conditions, the crack speeds are low, and the fracturing propagation pattern becomes similar to a quasi-static situation (see for instance Ravi-Chandar and Knauss, 1984, particularly figure 2, Ramulu and Kobayashi, 1985, especially figure 2, Agwai et al, 2011, particularly figure 13).

Even though the predictions obtained with Bobet's criterion generally correspond to the experimental observations, there are cases in which the results obtained with FROCK are not satisfactory, especially for coplanar double-flaw geometries (Fig. 1b). Therefore, to support future improvements of the failure criterion used in FROCK, stress-, strain- and energy-criteria were evaluated using a qualitative analysis performed with the FE code ABAQUS. The term qualitative is used to express the combination of quantitative analyses, in which stress and strain fields are obtained, with the visual comparison to what is observed in experiments.

This paper will first briefly review the Bobet stress-based criteria in Section 2, and subsequently present the Finite Element study which evaluates different crack initiation criteria in Section 3. The implementation of the new strain-based and the normal stress-dependent criteria in FROCK is discussed in Sections 4 and 5, respectively, and cracking patterns are compared with experimental observations made in molded gypsum specimens. In Section 6, the new parameter $\mathrm{L} / \mathrm{r}_{0}$ is implemented in FROCK and its impact on the cracking processes is evaluated.

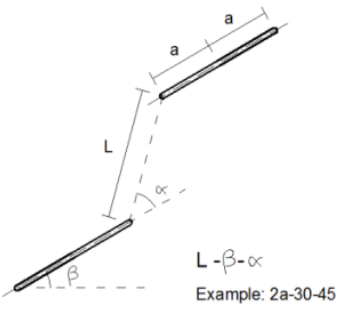

Fig. 1 Parameters used to describe double-flaw a) stepped and b) coplanar geometries. L is the ligament length, which is the distance between inner flaw tips expressed in terms of half flaw length $a=1 / 4$ inch in the current study; $\beta$ is the angle that the flaws make with the horizontal; $\alpha$ is the angle that the direction of the ligament between inner tips makes with the axes of the flaws. $\alpha$ is zero for coplanar geometries 


\section{Bobet's stress-based criterion}

\subsection{Definition of the criterion}

The stress-based criterion that FROCK currently uses was developed in 1997 by Bobet. It consists of a criterion for tensile crack initiation and propagation, which states that a crack will develop:

- At the tip of an existing flaw/crack

- In a direction $\theta$ in which the tangential stress $\sigma_{\theta}$ (Fig. 2) is maximum

$$
\begin{aligned}
& \left(\sigma_{\theta \max }\right) \\
& \frac{\partial \sigma_{\theta}}{\partial \theta}=0 \quad \frac{\partial^{2} \sigma_{\theta}}{\partial \theta^{2}}>0
\end{aligned}
$$

- When $\sigma_{\theta \max }=\sigma_{\theta}{ }^{\text {crit }}$, with $\sigma_{\theta}{ }^{\text {crit }}$ being the critical tangential stress

Note: $\sigma_{\theta \max }$ is obtained as a minimum value, because FROCK considers tensile stresses $\left(\sigma_{\theta}\right)$ to be negative.

And a criterion for shear crack initiation and propagation, which states that a crack will develop:

- At the tip of an existing flaw/crack

- In a direction $\theta$ in which the shear stress $\sigma_{\mathrm{r} \theta}$ (Fig. 2) is maximum $\left(\sigma_{\mathrm{r} \theta \max }\right)$

$$
\frac{\partial \sigma_{r \theta}}{\partial \theta}=0 \quad \frac{\partial^{2} \sigma_{r \theta}}{\partial \theta^{2}}<0
$$

- When $\sigma_{\mathrm{r} \theta \max }=\sigma_{\mathrm{r} \theta}{ }^{\text {crit }}$, with $\sigma_{\mathrm{r} \theta}^{\text {crit }}$ being the critical shear stress, also represented in some literature as $\tau^{\text {crit }}$.

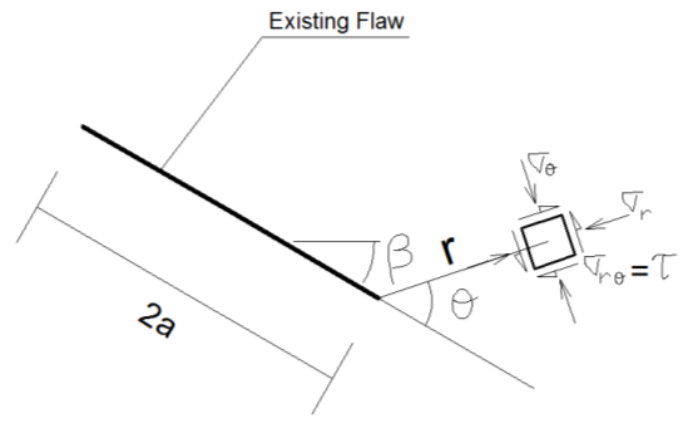

a)

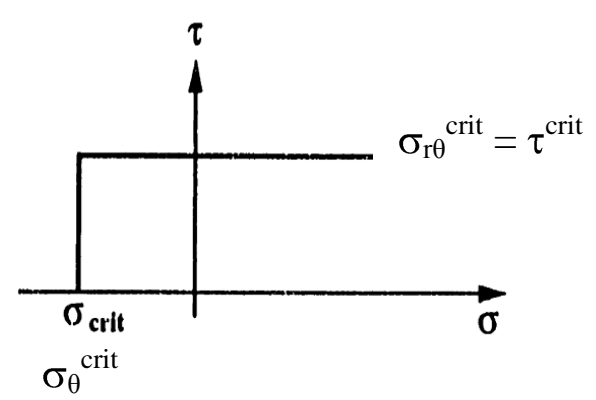

b)

Fig. 2 a) Stress field around a crack/flaw tip, showing the cylindrical stresses of an element radial to the flaw tip b) illustration of Bobet's stress-based criterion (from Bobet 1997) 
The stresses are computed at a distance $r$ from the flaw tip. This distance cannot be too small, since the stresses at $r=0$ tend to infinity. This means that there is a zone around the crack tip where linear elastic theory is not valid, since the applied stresses are greater than the resistance of the material. However, if this area is small enough when compared with the width of the specimen and with the size of the existing flaw, then Small Scale Yielding (SSY) conditions are valid and the problem can be analyzed as linearly elastic. Therefore, the plastic radius $r_{0}$ is considered a material parameter, but it can also be seen as a simple computational variable, since it is selected so that the computer code avoids the high stresses near the flaw tip.

Another important material parameter that was used by Bobet is the coefficient of friction $\mu(\delta)$, also defined as $\mathrm{f}(\delta)$ in some publications. When two surfaces of a given material are in contact, a shear stress $\tau=\mathrm{c}+\mu(\delta) \cdot \sigma_{\mathrm{n}}$ develops along their interface, with $\mu$ being the coefficient of friction, $\mathrm{c}$ being the cohesion and $\sigma_{\mathrm{n}}$ the normal stress acting on the interface. In FROCK, this coefficient is used to model existing closed flaws, and its value is a function of the slip $\delta$ along the two surfaces of the flaw. It should be noted that the coefficient of friction is not used in modeling the initiation of new cracks, but only to model the slippage of existing ones. The function that is usually implemented in the FROCK code in the present and past studies is shown in Fig. 3. In the case shown in this figure, after slippage occurs, $\mu(\delta)$ is constant.

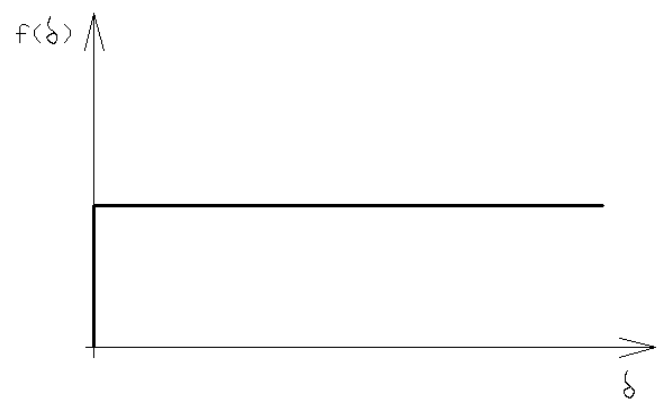

Fig. 3 Typical $\mu(\delta)$ or $\mathrm{f}(\delta)$ function used in the present and past FROCK studies

Therefore, the main parameters required by FROCK to model crack initiation and propagation according to Bobet's criterion are:

- Critical tangential stress $-\sigma_{\theta}{ }^{\text {crit }}$

- Critical shear stress $-\sigma_{\mathrm{r} \theta}{ }^{\text {crit }}$ 
- Plastic radius $-\mathrm{r}_{0}$

- Coefficient of friction for existing flaws $-\mu(\delta)$ or $\mathrm{f}(\delta)$

\subsection{Crack growth mechanism in FROCK}

In the current FROCK code, the length of the new crack $\mathrm{L}$ is independent of the plastic radius $r_{0}$ considered. As mentioned earlier, the plastic radius $r_{0}$ can be seen as a material property but also as a computational variable that determines the circle with center at an existing crack/flaw tip, at which stresses are computed in a given element, as shown in Fig. 4. The stresses computed in these elements are compared with the ones defined by the failure criterion being used, in order to determine whether a crack propagates or not.

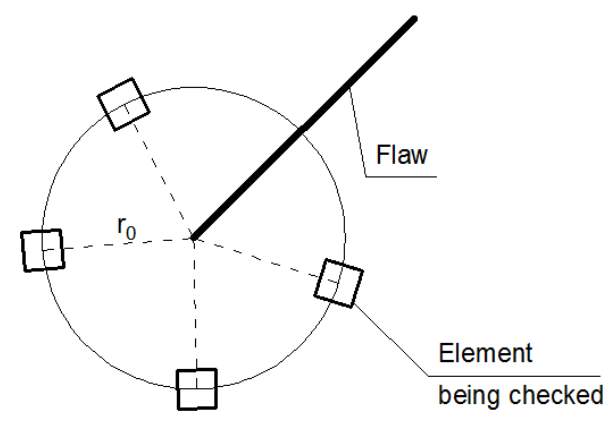

Fig. 4 Definition of the plastic radius $r_{0}$

If a crack propagates, the program introduces a new crack in the direction calculated. The previous FROCK code considers that the length $\mathrm{L}$ of this new crack is only a function of the size of the elements that defined the initial/existing flaw. In other words, if one defined that an existing flaw was 20 length units long and was divided into 10 elements i.e. each element is 2 length units long (2a), then the newly-formed crack is also 2 length units long $(\mathrm{L}=2 \mathrm{a})$, as shown in Fig. 5.

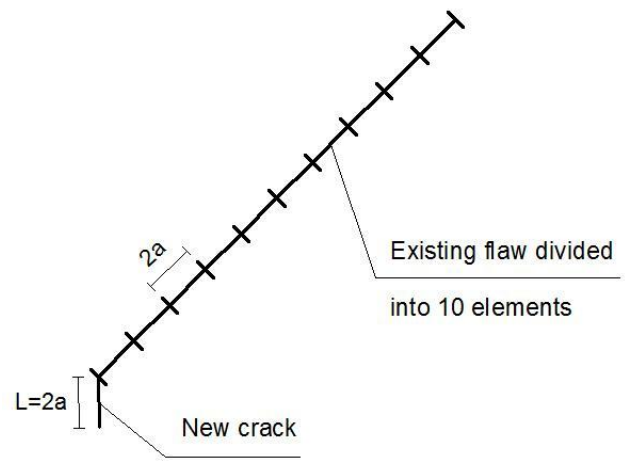

Fig. 5 Previous FROCK definition of the crack length of newly-formed cracks 
The load applied in most Bobet's and in the current FROCK simulations is compressive, vertically-oriented, and applied at an infinite distance from the flaws, in order to simulate the uniaxial compressive tests performed in molded gypsum specimens. The FROCK code first applies the full load in one step and then checks for non-linearities, or cracks, around the flaw tip, i.e. points where the failure criterion is met; if none are found, the full load is the solution of the problem, otherwise, the load applied is a percentage of the full load, corresponding to the minimum load at which a first non-linearity, or crack, is produced. This process is repeated iteratively until the full load is applied. This loading algorithm simulates very well the quasi-static loading rate used in the tests. As described by Wong (2008), the uniaxial load or strain was applied in three stages; for the gypsum specimens, a phase 1 was considered for an applied load between $0 \mathrm{lb}$ and $1,000 \mathrm{lb}$ at a rate of $0.1 \mathrm{in} / \mathrm{min}$, a phase 2 from $1,000 \mathrm{lbs}$ to $5,000 \mathrm{lbs}$ at a rate of $0.015 \mathrm{in} / \mathrm{min}$, and a phase $3 \mathrm{from} 5,000 \mathrm{lb}$ to failure at a rate of 2,300 lb/min. For more details on the FROCK code, refer to Chan (1986 and 1989) and Bobet (1997).

\subsection{Results obtained}

When implemented in FROCK, Bobet's criterion yielded very good results for some flaw geometries, since the crack patterns modeled corresponded to the ones obtained in the tests (see Bobet, 1998a, for results on several gypsum geometries). Results obtained with FROCK for the stepped geometry 2a-45-45 (refer to Fig. 1 for explanation of geometry) are shown in Fig. 6. 

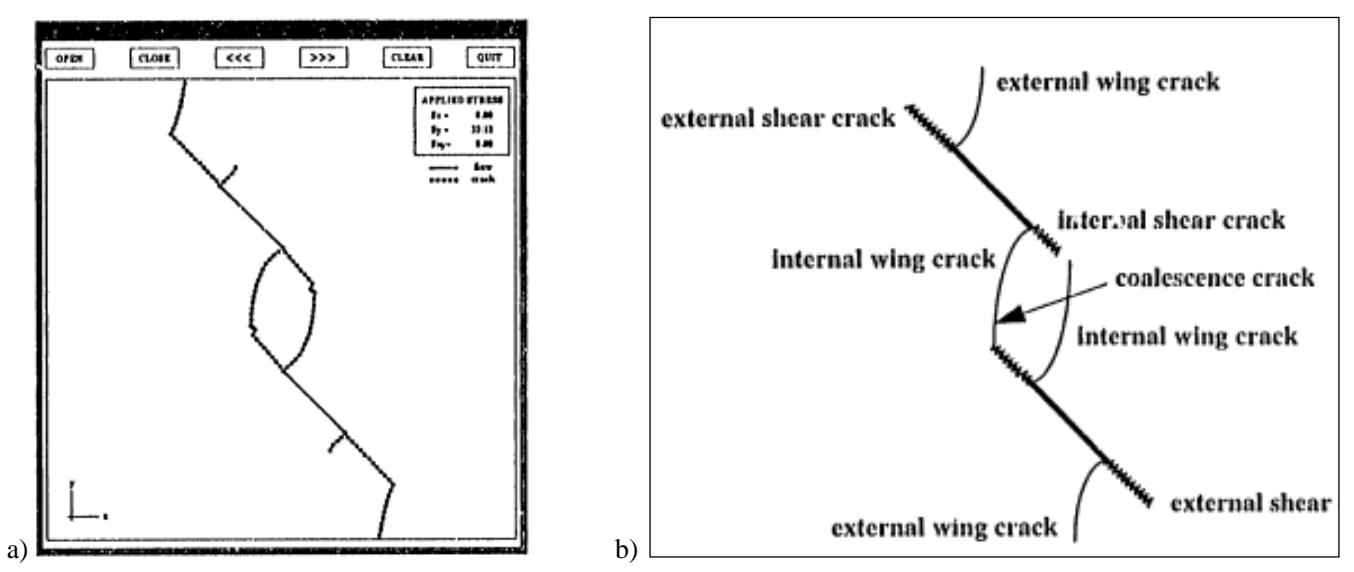

Fig. 6 a) FROCK (Bobet's stress-based criterion) simulation results (from Bobet 1997) b) Crack propagation pattern obtained experimentally in gypsum specimens for the geometry 2a-45-45 (from Bobet 1997)

However, other geometries are not as well modeled. For instance, FROCK fails to predict the crack propagation of the coplanar geometry $2 \mathrm{a}-75-0$, as can be seen in Fig. 7.

a)

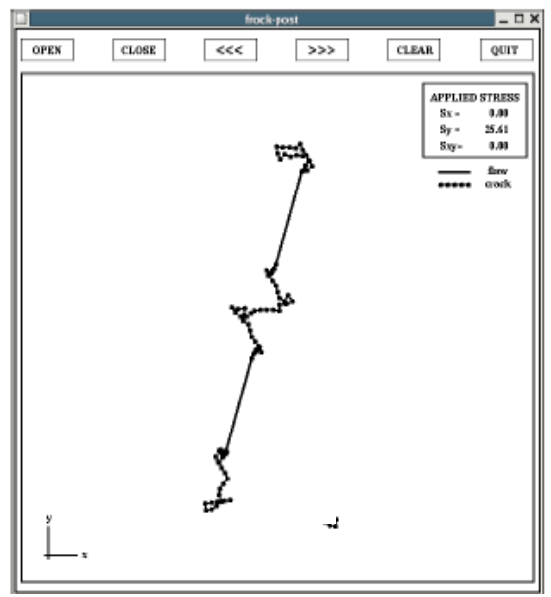

b)

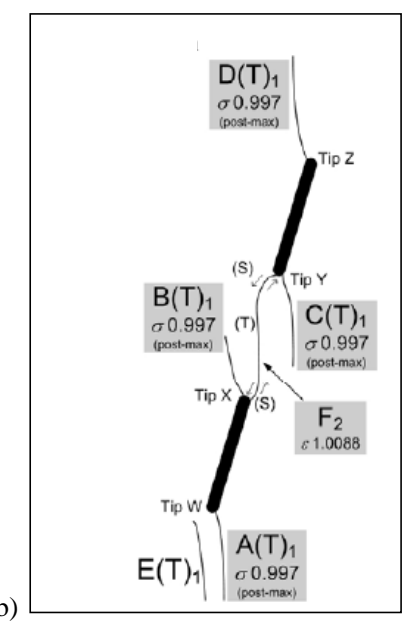

Fig. 7 a) FROCK (Bobet's stress-based criterion) simulation results (from Wong, 2008) b) test results for the flaw geometry 2a-75-0 in molded gypsum (from Wong, 2008). The letters A, B, $\mathrm{C}$... indicate the order by which the different cracks developed, $\mathrm{T}$ and $\mathrm{S}$ mean tensile and shear crack, respectively. $\sigma 0.997$, for instance, means that the crack developed at 0.997 of the failure stress.

It is therefore necessary to investigate if the Bobet criterion implemented in

FROCK can be improved such that all flaw geometries, stepped and coplanar, and the associated cracking processes, can be correctly captured. 


\section{Evaluation of existing crack initiation criteria using the Finite Element code ABAQUS}

\subsection{Methodology}

Crack initiation, -propagation and -coalescence processes were studied on two scales with a Finite Element code. The results of the larger scale study, which essentially considered the rectangle " $r$ " in Fig. 8, were reported in Gonçalves da Silva and Einstein (2012). This paper looks into crack initiation at a smaller scale, around the individual flaw tip. Specifically, the stress-, strain- and energyapproaches were studied using the finite element code ABAQUS. For this purpose, a circular path was created around a flaw tip, and stresses, strains and energy were calculated at several points along the path. Paths with different shapes were also studied in Gonçalves da Silva (2009), but the path shown in Figs. 9 and 11 is most informative. The overall model used in this study is presented in Fig. 8 and the specific path considered is shown in Fig. 9. The flaw geometry used in this study was 2a-30-30.

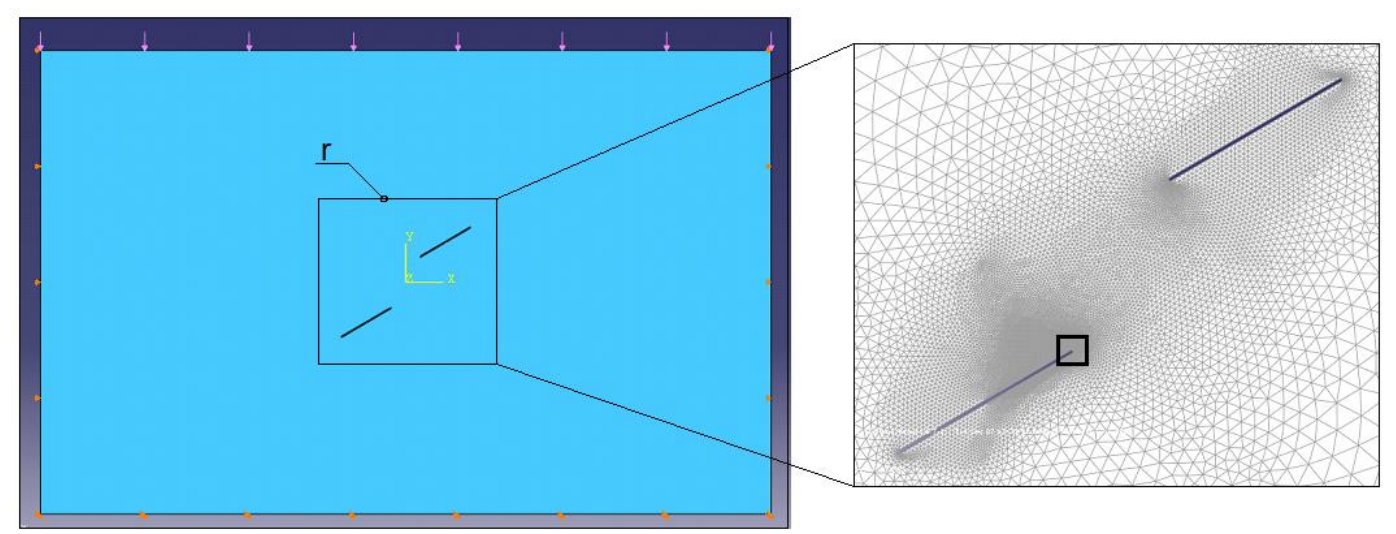

Fig. 8 Model used in the study of existing crack initiation criteria, showing the tip under investigation for the geometry 2a-30-30. Rectangle " $r$ " was used in the larger scale study

In order to facilitate the interpretation of the results, the path under investigation was divided into segments, or areas, where the different types of cracks are most likely to occur, according to test results obtained by Wong (2008) and Bobet (1997). The path was therefore divided into a wing crack, a shear crack and an anticrack segment/area. Since for the geometry and material being studied molded gypsum - anticracks did not often develop, the focus of this study will be primarily the shear and wing cracks. 


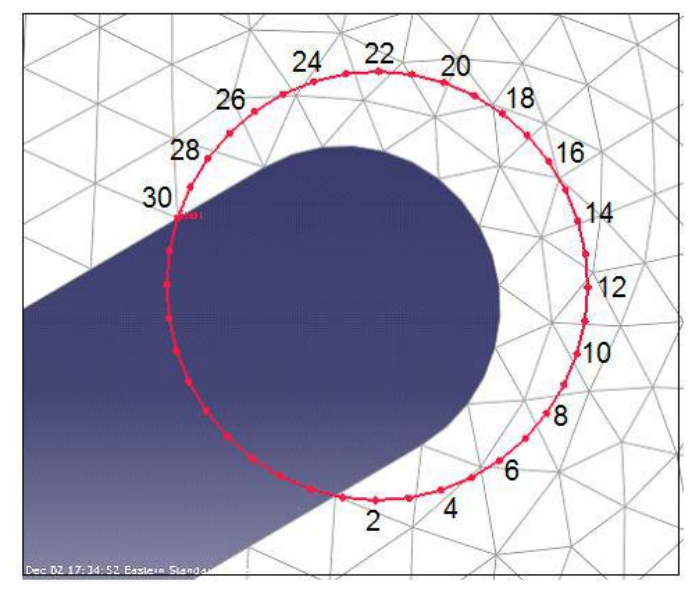

Fig. 9 Path and point IDs used in the investigation of existing crack initiation criteria

Figures $10 \mathrm{a}$ and $10 \mathrm{~b}$ show the crack propagation pattern for the stepped geometry 2a-30-30 using gypsum and marble specimens, respectively. The crack propagation of a marble specimen is shown in Figure 10b merely to illustrate the different crack propagation patterns obtained for different rock-like materials. Figure 10c shows the crack propagation pattern in gypsum, for the coplanar geometry 4a-30-0. Figure 11 illustrates the three different segments/areas considered along the analyzed path.

As can be seen at the tips highlighted with a circle in Fig. 10, three types of cracks initiating at the flaw tips can be identified:

- Wing crack (crack $\mathrm{D}(\mathrm{T})_{1}$ in Fig. 10a, crack B in Fig. 10b, crack $\mathrm{C}(\mathrm{T})_{1}$ in Fig. 10c) - a tensile crack initiating usually before the shear crack and from the upper face of the analyzed flaw tip;

- Shear Crack (crack $\mathrm{E}_{2}(\mathrm{~S})$ in Fig. 10a, crack $\mathrm{E}(\mathrm{S})_{2}$ in Fig. 10b) - Initiating usually after the wing crack, from the flaw tip end and in a direction that is approximately the same as the inclination $\left( \pm 20^{\circ}\right)$ of the existing flaw;

- Anticrack (crack $F_{3}$ (S near the tip and $T$ away from it) in Fig. 10c) - Initiates usually symmetrically to the wing crack that develops at the same tip. It is often considered as a shear crack that initiates making an angle greater than $45^{\circ}$ with the axis of the existing flaw.

Note that despite the focus of this section being a specific double-flaw geometry in molded gypsum, these fracturing mechanisms are observed in other materials and flaw geometries. Details on the many possible crack types and other materials are described in Wong and Einstein (2009a, b), as well as in Morgan et al. (2013) 


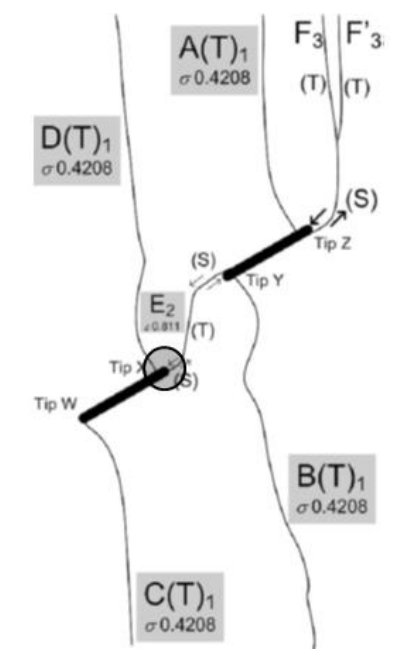

a)

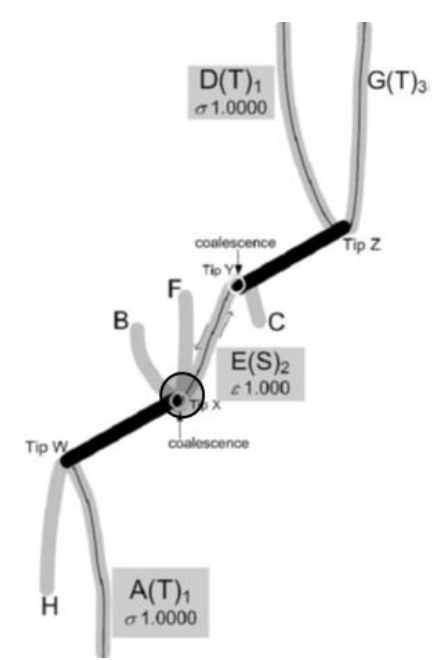

b)

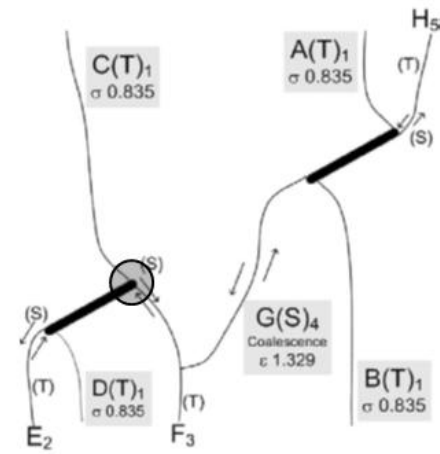

c)

Fig. 10 Location of wing and shear cracks developed from the flaw tips in a) the 2a-30-30 geometry for gypsum b) the 2a-30-30 geometry for marble and c) location of an anticrack in the geometry 4a-30-0 for gypsum - (from Wong, 2008). The letters A, B, C... indicate the order by which the different cracks developed, $\mathrm{T}$ and $\mathrm{S}$ mean tensile and shear crack, respectively. $\sigma 0.835$, for instance, means that the crack developed at 0.835 of the failure stress.

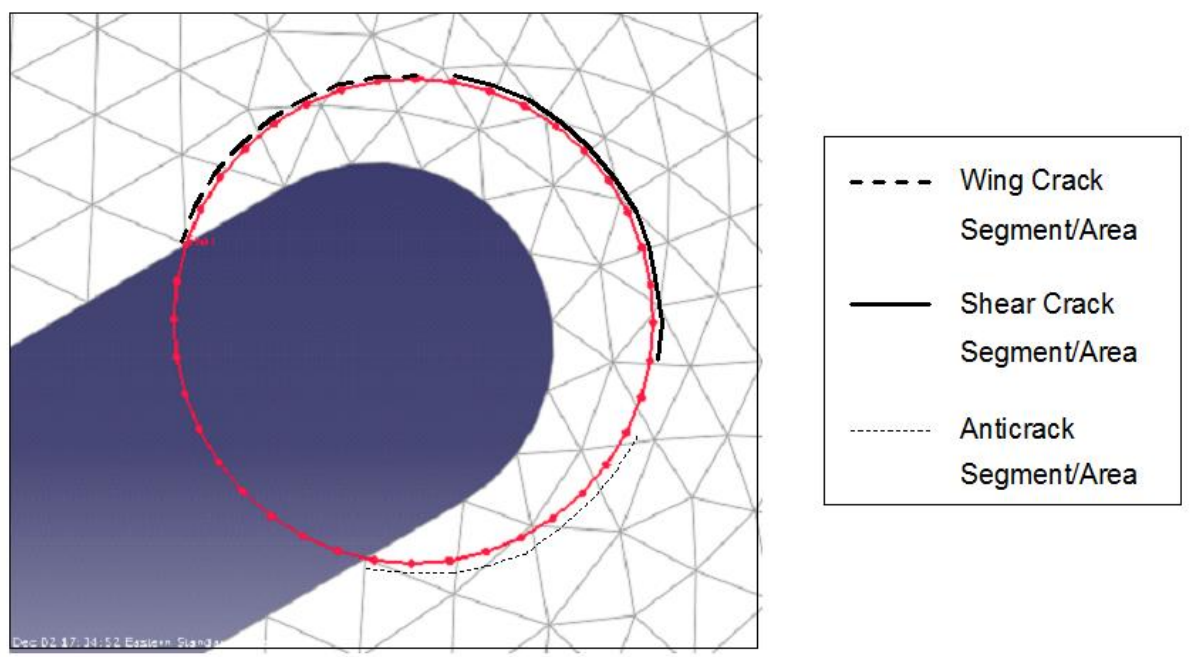

Fig. 11 Segments considered in the studied path in a 2a-30-30 geometry

In order to evaluate the stress-based approach, the maximum principal stresses $\left(\sigma_{\mathrm{I}}\right)$ and the maximum shear stresses $\left(\tau_{12}{ }^{\mathrm{max}}\right)$ were calculated along the predefined path. The maximum principal stresses $\left(\sigma_{\mathrm{I}}\right)$ were directly obtained from the ABAQUS output and were used to study the initiation of tensile cracks. The maximum shear stresses, calculated as $\tau_{12}{ }^{\max }=1 / 2 .\left(\sigma_{\mathrm{I}}-\sigma_{\mathrm{II}}\right)$, were used to study the initiation of shear cracks. $\sigma_{\mathrm{I}}$ and $\sigma_{\mathrm{II}}$ were obtained directly from ABAQUS output. The same rationale was followed for the strain-based approach, but calculating maximum principal strains $\left(\varepsilon_{\mathrm{I}}\right)$ to evaluate tensile crack initiation and maximum shear strains $\left(\gamma_{12}{ }^{\max }\right)$ to evaluate shear crack initiation. 
For the evaluation of energy-based criteria, the energy was calculated using different approaches. Two of them will be discussed in this paper (please refer to Gonçalves da Silva, 2009 for more information on the other approaches):

A) Traditional Approach - The two normal and the shear terms of the energy were calculated:

$$
\mathrm{E}_{\mathrm{A}}=1 / 2 \cdot \sigma_{11} \varepsilon_{11}+1 / 2 \cdot \sigma_{22} \varepsilon_{22}+1 / 2 \cdot \tau_{12} \gamma_{12}
$$

B) Maximum Principal Stresses and Strains Approach - Only the maximum principal stresses and strains are used. The objective of this approach is to isolate the principal tensile stresses and principal elongation strains - usually the maximum stresses and strains correspond to tensile stresses and elongation strains, respectively, even though this is not always true - in order to understand their role in the crack initiation:

$$
\mathrm{E}_{\mathrm{B}}=1 / 2 \sigma_{\mathrm{I}} \varepsilon_{\mathrm{I}}
$$

The following assumptions were made in the comparison of stress, strain and energy fields using ABAQUS:

- The material is considered to be homogeneous, isotropic and linearly elastic, with $\mathrm{E}=6,000 \mathrm{MPa}$ and $v=0.28$, based on tests performed in molded gypsum by Bobet (1997) and Wong (2008).

- The stress and strain fields are analyzed by comparing the relative values of the stresses and strains;

- The convention used in ABAQUS and in this study considers positive normal stresses and strains as tensile stresses and elongation strains, respectively. Also using ABAQUS convention, axis 1 is considered horizontal, axis 2 vertical, and axis 3 out-of-plane;

- Initial flaws are considered to be open with round tips (as in the laboratory tests).

\subsection{Results}

\section{Stress Approach}

The maximum principal stresses $\left(\sigma_{\mathrm{I}}\right)$ plotted along the studied path show one tensile maximum, corresponding to point 30 , located in a wing crack area, as shown in blue in Fig. 12. Point 12 is a compressive stress maximum for $\sigma_{\mathrm{I}}$. 
The maximum shear stress $\left(\tau_{12}{ }^{\text {max }}\right)$ plot reveals two maxima, corresponding to point 5 in the anticrack area - global maximum - and point 18 in the shear crack area. This result is illustrated in red in Fig. 12.

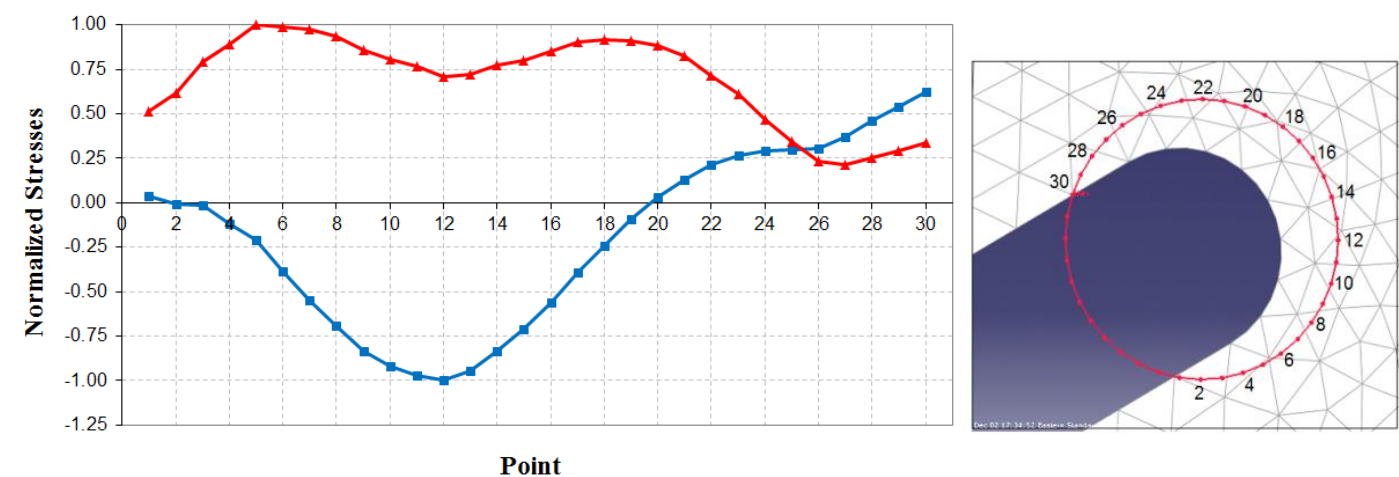

Fig. 12 Variation of $\sigma_{\mathrm{I}}$ (blue squares) and variation of $\tau_{12}{ }^{\text {max }}$ (red triangles) along the studied path

When compared with the experimental observations shown in Fig. 10, the initiation of wing, shear and anticrack cracks are acceptably predicted. However, the predicted anticrack would occur before the shear crack i.e. the shear stress at point 5 is higher than the shear stress at point 18 , which was not usually observed in the tests. The wing crack is likely to initiate from point 30 , since this is the point of maximum tensile principal stresses. This agrees with what was observed experimentally.

\section{Strain Approach}

As shown in blue in Fig. 13, the maximum principal strain $\left(\varepsilon_{I}\right)$ shows one global elongation maximum, corresponding to point 30 , and one local maximum at point 22 , both located in the wing crack region.

For the shear strains, it is expected that the plot matches perfectly the shear stress plot presented in red in Fig. 12, since there is a linear dependence between shear stresses and strains $\left(\gamma_{12}=\tau_{12} / G\right)$. Indeed, the shear stress and strain plots shown in red in Figs. 12 and 13 show the same maxima and the same shape. 

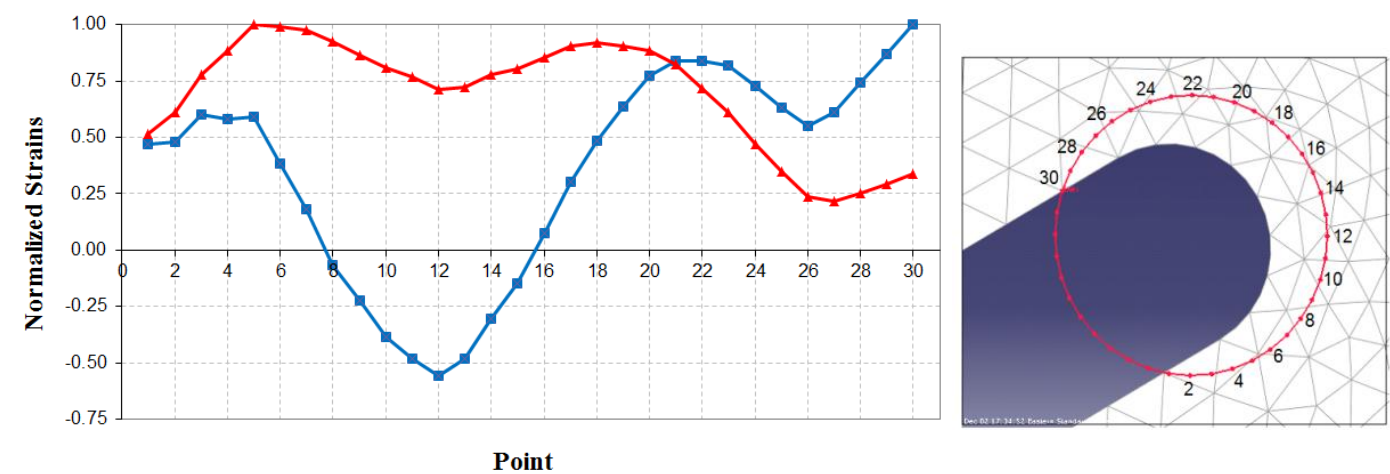

Fig. 13 Variation of $\varepsilon_{\mathrm{I}}$ (blue squares) and $1 / 2 \cdot \gamma_{12}{ }^{\max }$ (red triangles) along the studied

When compared with the experimental observations, one can state that the wing crack is well predicted occurring at the upper face of the analyzed flaw tip (point 30 or point 22). Wing cracks initiating at points 22 and 30 and in the area between these points were observed in the tests.

However, the predicted anticrack, corresponding to point 5, occurs before the shear crack corresponding to point 18 in Fig. 13, which is a sequence that was not usually observed in the actual tests.

\section{Energy Approach A}

Using the traditional energy approach, there is only a maximum between points 8 and 11, as shown in red in Fig. 14. This corresponds to the area between the shear crack and anticrack segment. The results do not agree with what was observed in the tests, since no crack is predicted to initiate in the wing or shear crack segments.
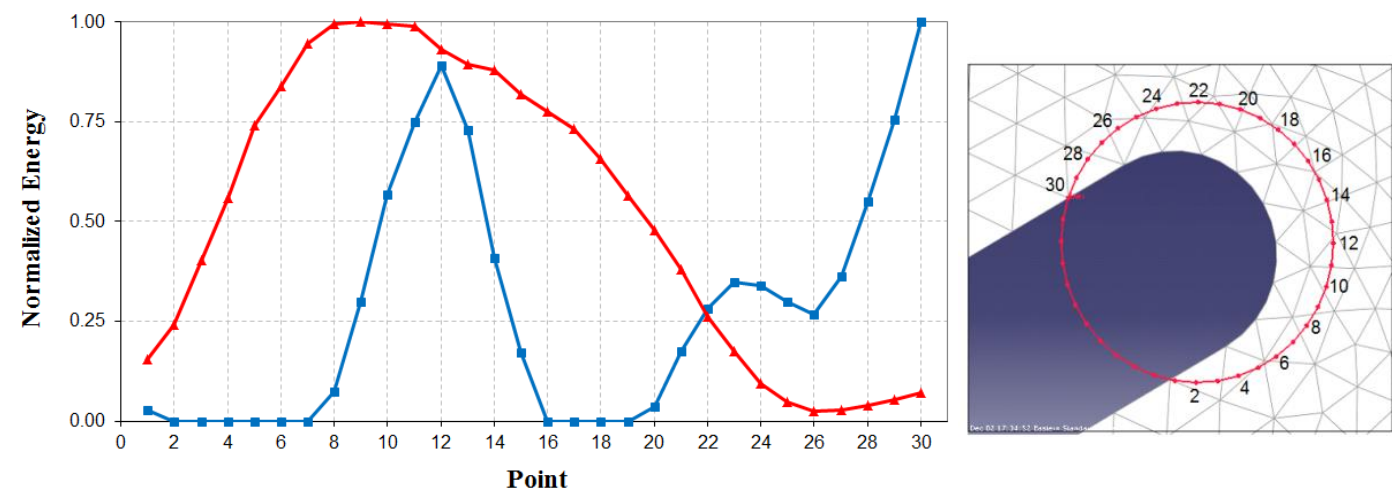

Fig. 14 Variation of $\mathrm{E}_{\mathrm{A}}$ (red triangles) and $\mathrm{E}_{\mathrm{B}}$ (blue squares) along the studied path 


\section{Energy Approach B}

Using this approach, and as shown in blue in Fig. 14, point 30 is a global maximum and point 12 a local maximum. Point 30 is located in the wing crack segment while point 12 is located at one end of the shear crack segment. On the one hand, this method predicts very well the place where wing cracks initiate in reality. On the other hand, since only the energy term $1 / 2 \cdot \sigma_{I} \varepsilon_{I}-$ i.e. usually tensile stresses and elongation strains - is studied, one would expect that only tensile cracks would be predicted. However, predicting a tensile crack at point 12 does not correspond to the experimental results, as only shear cracks initiated in this region. Therefore, the types of cracks modeled using this approach only partially correspond to the experimental results.

Summarizing, both stress and strain approaches predict the initiation of wing and shear cracks at the locations observed in the tests, while none of the energy approaches could do so. While the stress and strain-based criteria presented here are capable of separating the tensile from the shear behavior, this separation cannot be easily done in the energy criteria studied, since there are usually three terms involved in the calculation of the energy.

Based on the results obtained in this section and in Gonçalves da Silva and Einstein (2012), two modifications of the FROCK code were implemented and investigated:

1- A strain-based criterion, analogous to Bobet's stress-based criterion, was included (see Section 4);

2- The original stress-based criterion was extended by making the critical shear stress dependent on the applied normal stress (Note from Fig. $2 b$ that $\sigma_{\mathrm{r} \theta}{ }^{\text {crit }}=$ constant for the original Bobet stress-based criterion) (see Section $5)$;

The proposed criteria and their fracturing propagation results in molded gypsum specimens are presented in the following sections. 


\section{Evaluation of a proposed strain-based crack initiation and propagation criterion using the Displacement Discontinuity Method (DDM) code FROCK}

\subsection{Methodology}

The strain-based criterion implemented in FROCK is based on the stress-based criterion proposed by Bobet (1997). Similar to what was considered in Bobet's criterion, the proposed strain-based criterion also predicts tensile and shear cracks. Therefore, as in Bobet's approach, there is a condition for tensile crack initiation and propagation and another for shear crack initiation and propagation. Considering a strain field around a flaw tip, as illustrated in Fig. 15, a tensile crack will initiate or propagate:

- At the tip of an existing crack

- In a direction $\theta$ in which $\varepsilon_{\theta}$ is $\max \left(\varepsilon_{\theta \max }\right)$

$$
\frac{\partial \varepsilon_{\theta}}{\partial \theta}=0 \quad \frac{\partial^{2} \varepsilon_{\theta}}{\partial \theta^{2}}>0
$$

- When $\varepsilon_{\theta \max }=\varepsilon_{\theta}{ }^{\text {crit }}$, with $\varepsilon_{\theta}{ }^{\text {crit }}$ being the critical tangential strain

Note: $\varepsilon_{\theta \max }$ is obtained as a minimum value, because FROCK considers elongation strains $\left(\varepsilon_{\theta}\right)$ to be negative in FROCK.

And a shear crack will initiate or propagate:

- At the tip of an existing crack

- In a direction $\theta$ in which $\gamma_{\mathrm{r} \theta}$ is $\max \left(\gamma_{\mathrm{r} \theta \max }\right)$

$$
\frac{\partial \gamma_{r \theta}}{\partial \theta}=0 \quad \frac{\partial^{2} \gamma_{r \theta}}{\partial \theta^{2}}<0
$$

- When $\gamma_{\mathrm{r} \theta \max }=\gamma_{\mathrm{r} \theta}{ }^{\text {crit }}$, with $\gamma_{\mathrm{r} \theta}{ }^{\text {crit }}$ being the critical shear strain

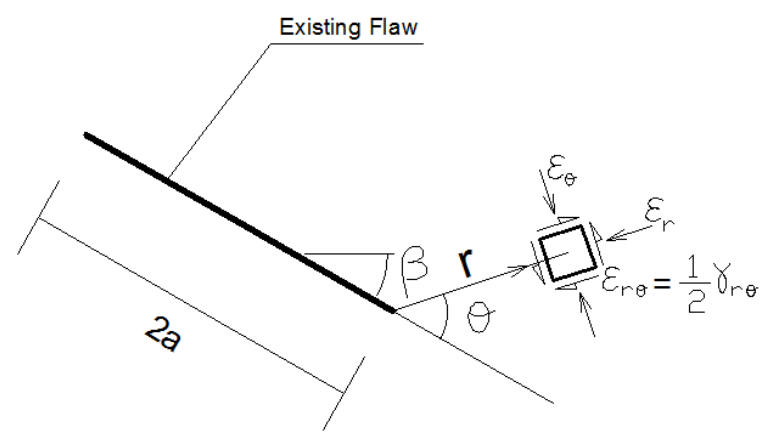

Fig. 15 Strain field around a crack tip, showing the cylindrical strains of an element radial to the flaw tip 
The parameters required by FROCK to model crack initiation and propagation according to the proposed strain-based criterion are:

- Critical tangential strain $-\varepsilon_{\theta}{ }^{\text {crit }}$

- Critical shear strain $-\gamma_{\mathrm{r} \theta}{ }^{\text {crit }}$

- Plastic radius $-r_{0}$

- Coefficient of friction for existing flaws $-\mu$

The strain-based criterion was used to analyze five molded gypsum geometries: 2a-30-0, 2a-30-30, 2a-45-45, 2a-75-0 and a-30-0, as shown in Fig. 16. Geometries 2a-45-45 and a-30-0 had already been successfully modeled by Bobet (1998a). Hence, they are used in this study to validate the results obtained with the proposed crierion. The coplanar geometries $2 \mathrm{a}-30-0,2 \mathrm{a}-75-0$ and $\mathrm{a}-30-0$ were selected because Wong (2008) tried to unsuccessfully model them in FROCK using Bobet's stress-based approach.

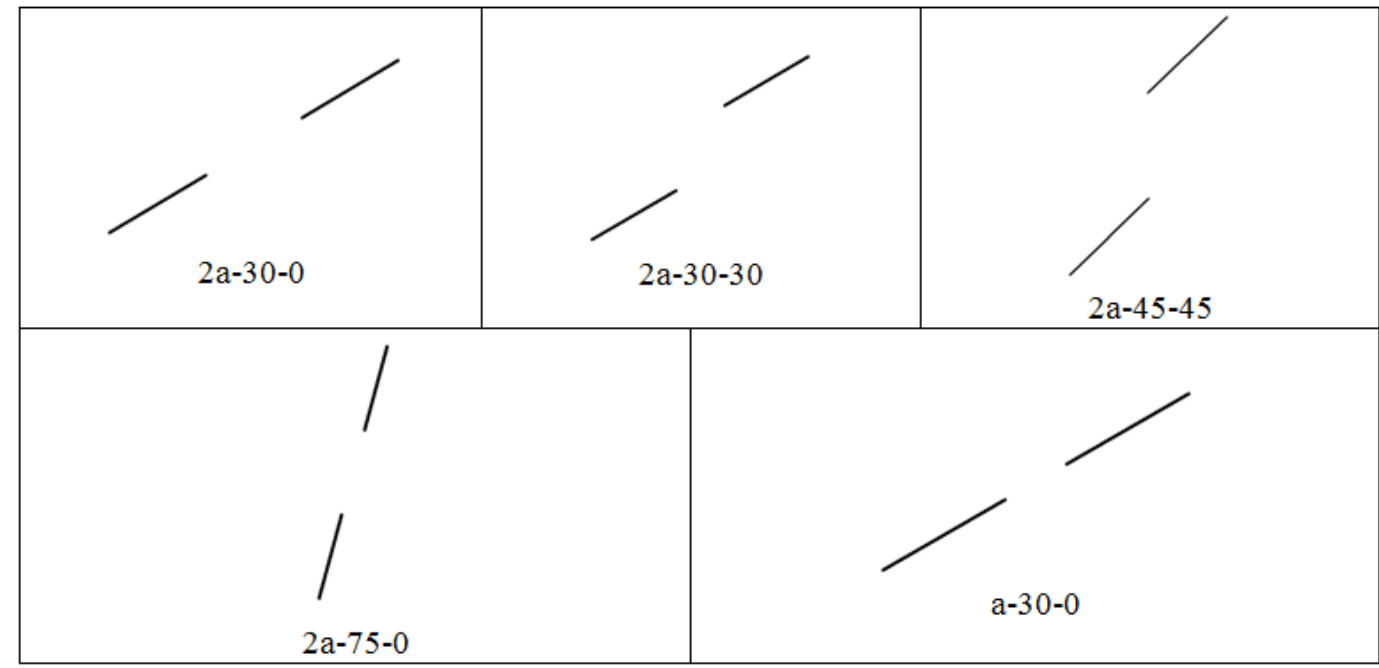

Fig. 16 - Geometries used to study the strain-based criterion implemented in FROCK

The following assumptions and considerations were made in order to evaluate the strain-based criterion implemented in FROCK:

- The medium was considered homogeneous, isotropic and linearly elastic with $\mathrm{E}=6,000 \mathrm{MPa}$ and $v=0.28$, based on tests performed in molded gypsum by Bobet (1998a) and Wong (2008)

- Uniaxial vertical load was applied at infinity;

- Initial flaws were considered open, as in the tests;

- Cracks initiate only from the flaw tips; 
- The main focus was the crack initiation and propagation pattern. Less emphasis was put on the stresses at which different events occur.

For the five geometries studied, five different requirements were used in order to judge whether a given observed fracturing pattern was well modeled in FROCK:

a) Wing cracks should be the first cracks to initiate;

b) Angle of wing cracks should be reasonably similar to what was observed in the tests;

c) Shear cracks should initiate from the crack tip, after wing cracks have developed;

d) Crack coalescence should occur;

e) Type of coalescence crack should be similar to what was observed in the tests

\subsection{Results}

The results obtained with the proposed strain-based criterion are compared with Bobet's stress-based criterion, as well as with experimental observations. Since both strain and stress-based criteria have four input parameters, a parametric study was first made in order to select the set of parameters that would yield the best overall results. The parametric study consisted of several iterative stages in which three parameters were fixed and one was varied in each stage. Only a small range of values was used for each parameter, based on the parameters already calibrated by Bobet (1997 and 1998a). The results were considered satisfactory and the iterations stopped when the modeled patterns of crack initiation, propagation and coalescence were similar to the patterns observed in the tests, according to the five requirements described in section 4.1. This methodology was followed for the five geometries studied and a single set of parameters was selected for which the best results were obtained for the greatest number of geometries. For more details on this parametric study, please refer to Gonçalves da Silva (2009). The set of input parameters that yielded the best overall results for the Bobet's stress-based criterion was based on Bobet's (1997 and 1998a) results: 
- $\sigma_{\theta}{ }^{\text {crit }}=-18.1 \mathrm{MPa}$

- $\quad \sigma_{\mathrm{r} \theta}{ }^{\text {crit }}=29.5 \mathrm{MPa}$

- $\mathrm{r}_{0}=0.023 \mathrm{~cm}$

- $\mu=0.70$

For the strain-based criterion, the set of input parameters selected was:

- $\varepsilon_{\theta}{ }^{\text {crit }}=-0.0025$

- $\quad \gamma_{\mathrm{r} \theta}{ }^{\mathrm{crit}}=0.0086$

- $\mathrm{r}_{0}=0.017 \mathrm{~cm}$

$-\mu=0.70$

In order to better illustrate the results obtained, two stages of crack propagation are shown in Table 1. For the cases where coalescence occurred, coalescence was considered the second stage of propagation. The same table also shows experimental observations in molded gypsum specimens and results obtained with Bobet's stress-based criterion. In this way, it is easier to compare the two criteria. As can be observed in Table 1, there is a good agreement between the experimental observations and the results obtained with FROCK using the strainbased criterion, for the selected set of parameters. The results obtained for each geometry are now individually described, based on the five requirements indicated in the previous section:

- Geometry 2a-30-0: For the stress-based criterion, requirements a) and b) are met. None of the other requirements are met in the stress-based criterion and none of the five are met for the strain-based criterion;

- Geometry 2a-30-30: The five requirements are met for the stress-based and strain-based criteria. In both criteria, the shear crack that develops from the inner flaw tips is slightly longer than in the tests, and there are two coalescence tensile cracks instead of one in the stress-based criterion. Bearing in mind that there are also slight differences between tests with the same geometry (refer to Bobet, 1997 and Wong, 2008), these differences are considered acceptable. Hence, the agreement with the experimental observations is considered to be reasonably good.

- Geometry 2a-45-45: The five requirements are met using both stress-based and strain-based approaches. 
- Geometry 2a-75-0: None of the five requirements is met using the stressbased criterion. For the strain-based approach, the wing cracks developed in a direction reasonably similar to the tests, i.e. requirement b). The wing cracks and shear cracks initiate almost simultaneously from the crack tip. Requirements a) and c) state that wing cracks should initiate before the shear cracks from the tip, which means these requirements are not fully met. Requirements d) and e) are met, since the coalescence through tensile crack(s) observed in the tests is well-modeled in FROCK. Even though requirements a) and c) are not fully met, this geometry is considered to be reasonably well-modeled.

- Geometry a-30-0: The stress-based approach models coalescence through two different cracks, initiating from one inner flaw tip and reaching the opposite inner tip. This type of coalescence was not observed in the tests, therefore requirement e) is not met. The strain-based approach meets the five requirements, despite the wing crack orientation (requirement b)) being slightly different from the tests.

The poor results obtained with geometry 2a-30-0 indicate that it may be more difficult to obtain reasonable results for coplanar geometries, as this frequently also occurs in the stress-based criterion (Bobet, 1998a, Wong, 2008). However, the strain-based criterion yielded good results for the two other coplanar geometries, 2a-75-0 and a-30-0. This was never achieved with the stress-based criterion for the selected set of parameters, which indicates that the strain-based criterion may be capable of modeling the cracking processes better than the stressbased criterion. 
Table 1 Crack propagation results - Experimental results using molded gypsum, FROCK prediction using Bobet's stress-based criterion and the proposed strain-based criterion for different flaw geometries. *) denotes Wong's (2008) and **) denotes Bobet's (1997) experimental results. The letters A, B, C... indicate the order by which the different cracks developed, T and S mean tensile and shear crack, respectively; W represent wing crack, a type of tensile crack. $\sigma 0.7072$, for instance, means that the crack developed at 0.7072 of the failure stress.

Ge0metry




\section{Evaluation of a proposed normal stress- dependent crack initiation and propagation criterion using the Displacement Discontinuity Method (DDM) code FROCK}

\subsection{Methodology}

The proposed normal stress-dependent criterion models the dependence between the resisting shear stress and the applied normal stress, as illustrated in Fig. 17b. In Fig. 17a and 17b, the fundamental characteristics of the stress-based criterion developed by Bobet and of the proposed normal stress-dependent criterion are shown.
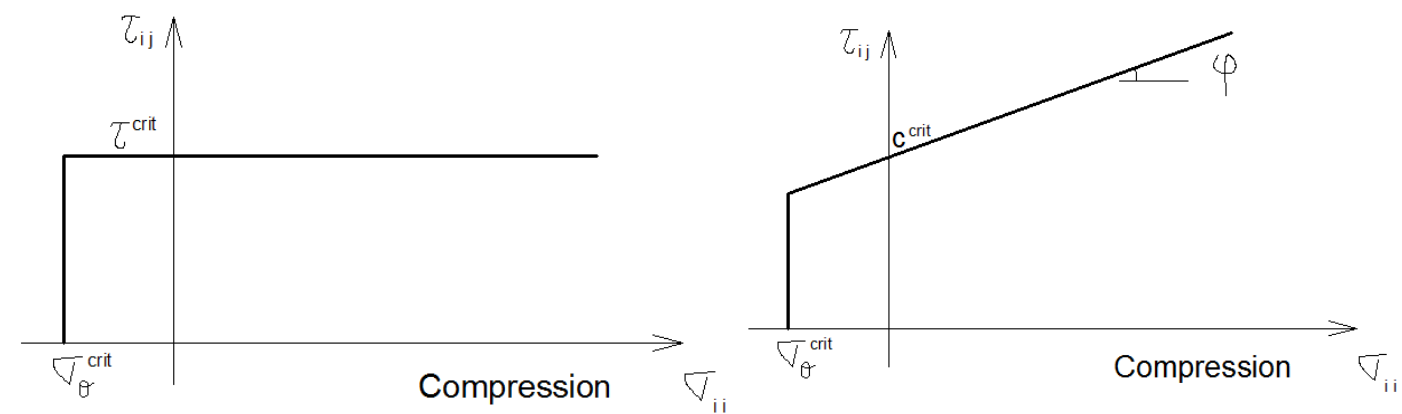

a)

b)

Fig. 17 a) Failure surface for the stress-based criterion b) Failure surface for the proposed normal stress-dependent criterion

For tensile failure, the stress-dependent criterion is similar to the stress-based criterion developed by Bobet. A failure surface and a Mohr circle are shown in Fig 18a to illustrate this kind of failure. When the tangential stress $\sigma_{\theta}$ of an element oriented radially to the crack tip (Fig 18b) reaches the critical tangential stress of the material $\left(\sigma_{\theta}{ }^{\text {crit }}\right)$, then tensile failure occurs. As can be seen in Fig 18a, the Mohr circle for such a "radial" element at imminent failure is not necessarily tangential to the tensile failure line defined by $\sigma_{\theta}{ }^{\text {crit }}$. For it to be tangential to the failure surface, the direction of the element would not necessarily be "radial", as the element shown in Fig. 18b, but rotated a certain angle. 


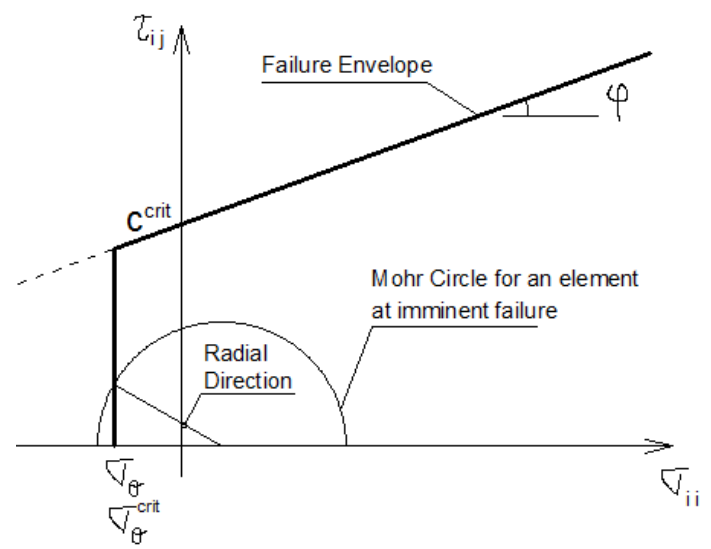

a)

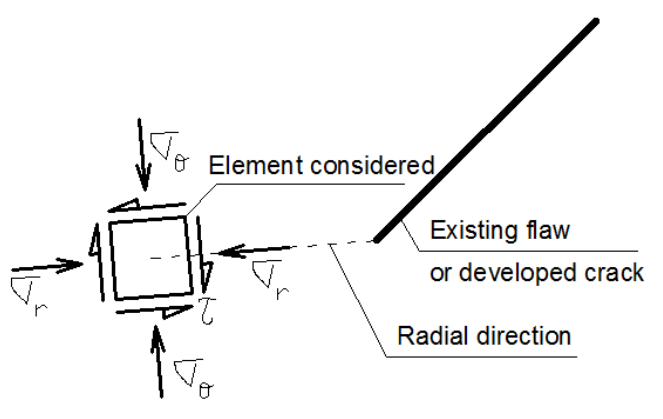

b)

Fig. 18 a) Definition of tensile failure for the normal stress-dependent criterion b) Example of a radial element and the acting cylindrical stresses considered in the normal stress-dependent criterion

The parameters necessary to model tensile failure according to this criterion are then:

Acting stresses:

- $\quad$ Tangential stress $-\sigma_{\theta}$

Resistance parameters:

- Critical tangential stress $-\sigma_{\theta}{ }^{\text {crit }}$

For shear failure to occur in the proposed normal stress-dependent criterion, the only necessary requirement is that the shear stress $\sigma_{\mathrm{r} \theta}$ or $\tau$ reaches the inclined (or horizontal, for $\varphi=0^{\circ}$ ) failure envelope. The failure surface and a Mohr circle at imminent shear failure are shown in Fig. 19a. The element shown in Fig. 19b illustrates its radial direction and the acting cylindrical stresses. 


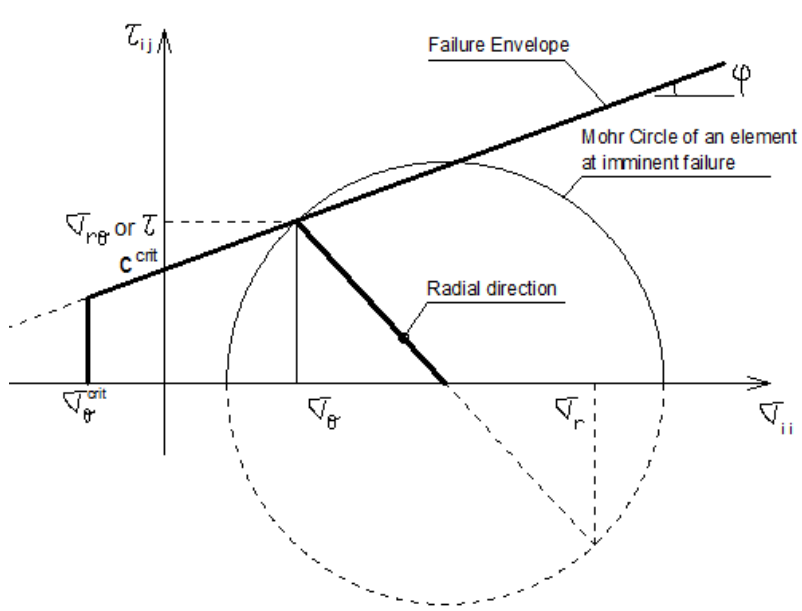

a)

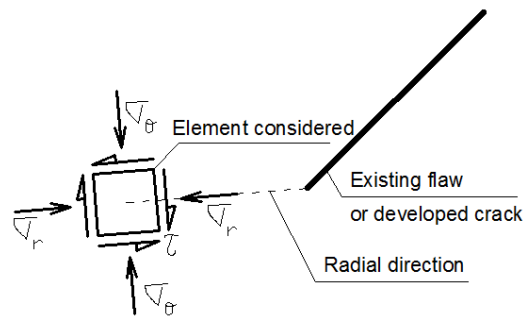

b)

Fig. 19 a) Definition of shear failure for the proposed stress-dependent criterion b) Example of a radial element and the acting cylindrical stresses considered in the proposed criterion

As can be seen, the acting stresses involved are the shear stress $\tau$ and the tangential stress $\sigma_{\theta}$.The parameters necessary to model shear failure according to this criterion are then:

Acting stresses:

- $\quad$ Tangential stress $-\sigma_{\theta}$

- $\quad$ Shear stress $-\tau$

Resistance parameters:

- Cohesion $-\mathrm{c}^{\text {crit }}$

- Friction angle $-\varphi$

Note: The cohesion used in the normal stress-dependent criterion was defined as $\mathrm{c}^{\text {crit }}$ in order to distinguish from the cohesion $\mathrm{c}$ used to describe the slippage and consequent shear stress that develops between the surfaces of existing flaws (see Section 2).

The following assumptions and considerations were made in order to evaluate the normal stress-dependent criterion implemented in FROCK:

- The medium was considered homogeneous, isotropic and linearly elastic with $\mathrm{E}=6,000 \mathrm{MPa}$ and $v=0.28$, based on tests performed in molded gypsum by Bobet (1998a) and Wong (2008)

- Uniaxial vertical load was applied at infinity;

- Initial flaws were considered open, as in the tests; 
- Cracks initiate only from the flaw tips;

- The main focus was the crack initiation and propagation pattern. Less emphasis was put on the stresses at which different events occur.

\subsection{Results}

In order to evaluate the proposed normal stress-dependent criterion, special attention was given to the influence of the friction angle on the cracking patterns obtained. For this purpose, the friction angle was varied while the remaining parameters were fixed. These parameters were selected based upon a parametric study which followed the methodology described in 4.2 for the strain-based criterion. Because of the large number of parameters necessary to define this criterion, the parametric study was very computationally-intensive and was therefore carried out only for a single geometry $2 \mathrm{a}-45-45$. This geometry was selected because very good results were already obtained using Bobet's stressbased criterion. Therefore, by using the $2 \mathrm{a}-45-45$ geometry, it would be possible to better judge the impact of the new parameter $\varphi$.

Based on the parametric study carried out, the following set of parameters was used. As can be noted, $\sigma_{\theta}{ }^{\text {crit }}$, $c^{\text {crit }}$ and $\mu$ are similar to Bobet's (1998a) stress-based criterion, as shown in section 4.1.

$$
\begin{array}{ll}
- & \sigma_{\theta}{ }^{\text {crit }}=-18.1 \mathrm{MPa} \\
- & c^{\text {crit }}=29.5 \mathrm{MPa} \\
- & r_{0}=0.035 \mathrm{~cm} \\
- & \mu=0.70 \\
- & \varphi=0^{\circ}, 5^{\circ}, 25^{\circ}
\end{array}
$$

It should be emphasized that the coefficient of friction $\mu$ represents the friction between existing cracks, while the friction angle $\varphi$ is used to model the envelope of the failure criterion.

By comparing the modeled cracking patterns in Table 2 with the experimental observations shown in Fig. 6b, it is clear that the best results are obtained for very low friction angles, i.e. around $0^{\circ}$. While the wing cracks are generally well modeled by FROCK, the shear cracks are not reasonably modeled when the friction angle is increased. 
A possible reason for this result is that the $\varphi$-dependent failure criterion, which one uses frequently and with good results to model macroscale failures, might not be adequate to model microscale failures, such as the cases under study here. In other words, the results obtained here indicate that for the microscale case, the critical shear stress at which a given material - particularly rock - fails appears not to depend upon the normal stress applied.

Table 2 Results of the stress-dependent criterion for different friction angles for flaw geometry 2a45-45

\begin{tabular}{|c|c|c|}
\hline \multicolumn{3}{|c|}{ Stress-dependent criterion $\left(\sigma_{\theta}{ }^{\text {crit }}=18.1 \mathrm{MPa}, \mathrm{c}=29.5 \mathrm{MPa}\right.$ kept constant $)$} \\
\hline \multirow{2}{*}{$\varphi\left({ }^{\circ}\right)$} & \multicolumn{2}{|c|}{ Visual assessment } \\
\hline & Comments & Propagation \\
\hline 0 & - Very good result & \\
\hline 5 & $\begin{array}{l}\text { - Good wing crack propagation } \\
\text { - Odd shear crack } \\
\text { - No coalescence }\end{array}$ & \\
\hline 25 & $\begin{array}{l}\text { - Good wing crack propagation } \\
\text { - Shear crack too steep } \\
\text { - Coalescence } \neq \text { tests }\end{array}$ & \\
\hline
\end{tabular}




\section{Evaluation of the influence of the ratio between new crack length and plastic radius $\left(\mathrm{L} / \mathrm{r}_{0}\right)$ on the modeled cracking processes}

\subsection{Methodology}

The ratio between the length of the new cracks $L$ and the plastic radius $r_{0}$ was introduced as a new input parameter in FROCK, and its influence on the crack initiation and propagation was assessed.

The fact that the length of the newly-formed cracks is independent of the plastic radius (see section 2.2) might be a source of errors. This is so, because for $2 \mathrm{a} \gg$ $\mathrm{r}_{0}$ or $2 \mathrm{a} \ll \mathrm{r}_{0}$, the point where the stress is calculated (at a distance $\mathrm{r}_{0}$ from the crack tip) might not be representative of the crack that propagates thereafter. This can be better explained by Fig. 20 .

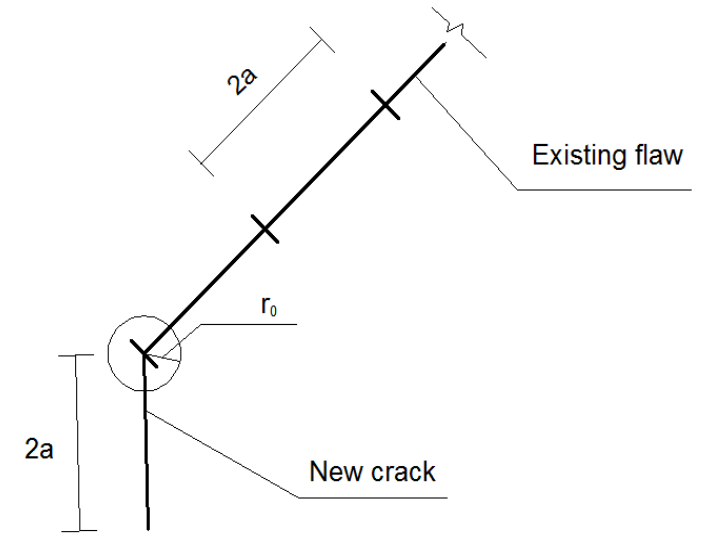

Fig. 20 Plastic radius independent of the length of a newly-formed crack, as previously considered in FROCK. The length of the new crack $-2 a$ - is only dependent of the length of the elements of the existing flaw, and independent of the plastic radius $r_{0}$.

In the proposed modification of FROCK, the length L of the newly-formed crack is now dependent of the plastic radius $r_{0}$. Therefore, once the plastic radius is varied, the length of the newly-formed crack is also modified, proportionally to $\mathrm{r}_{0}$, depending of the ratio $\mathrm{L} / \mathrm{r}_{0}$ considered.

For the geometry $2 \mathrm{a}-45-45$, the crack propagation results obtained with the normal stress-dependent criterion for different ratios $\mathrm{L} / \mathrm{r}_{0}$ were compared with experimental observations. 


\subsection{Results}

Three different ratios of $\mathrm{L} / \mathrm{r}_{0}=1.0,2.0$ and 2.5, as illustrated in Fig. 21a, 21b and 21c, were analyzed. Using the parameters obtained from the parametric study of the normal stress-dependent criterion in 5.2, three different ratios of $\mathrm{L} / \mathrm{r}_{0}$ were tested, $\mathrm{L} / \mathrm{r}_{0}=1.0,2.0$ and 2.5. The following parameters were therefore used:

$$
\begin{array}{ll}
- & \sigma_{\theta}=-18.1 \mathrm{MPa} \\
- & c=29.5 \mathrm{MPa} \\
- & \mathrm{r}_{0}=0.035 \mathrm{~cm} \\
- & \mu=0.70 \\
- & \varphi=0^{\circ}
\end{array}
$$

The results for $\mathrm{L} / \mathrm{r}_{0}=1.0,2.0$ and 2.5 are shown in Figs. 22 and 23, respectively.

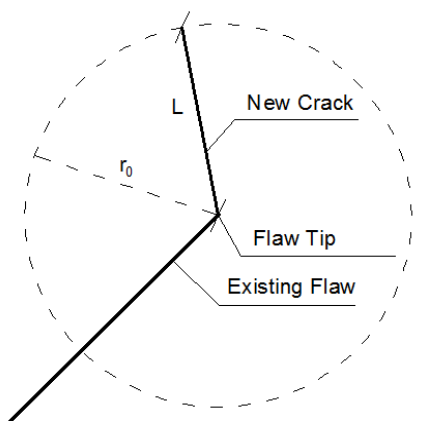

a)

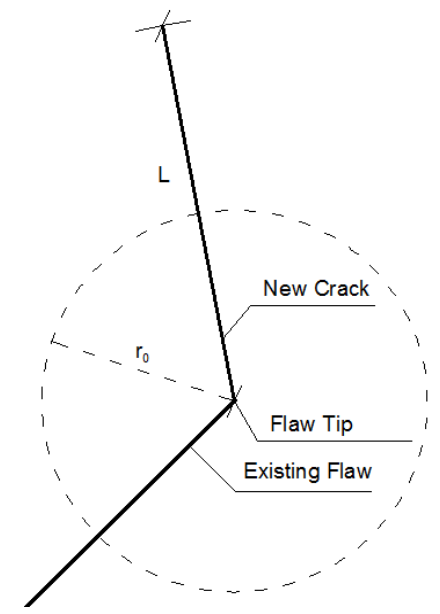

b)

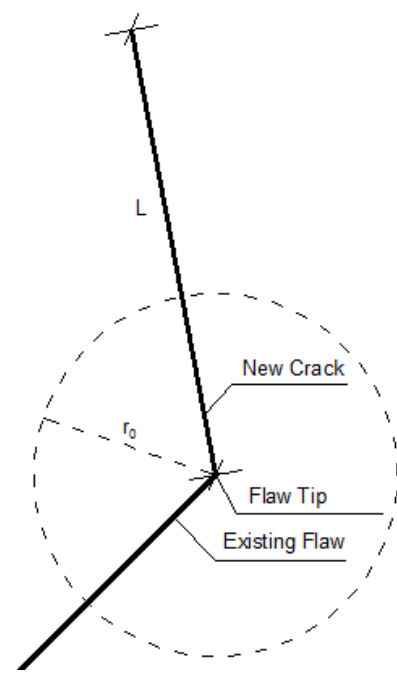

c)

Fig. 21 Ratios a) $\mathrm{L} / \mathrm{r}_{0}=1.0$, b) $\mathrm{L} / \mathrm{r}_{0}=2.0$, c) $\mathrm{L} / \mathrm{r}_{0}=2.5$ used to evaluate the effect of $\mathrm{L} / \mathrm{r}_{0}$ on the cracking patterns 

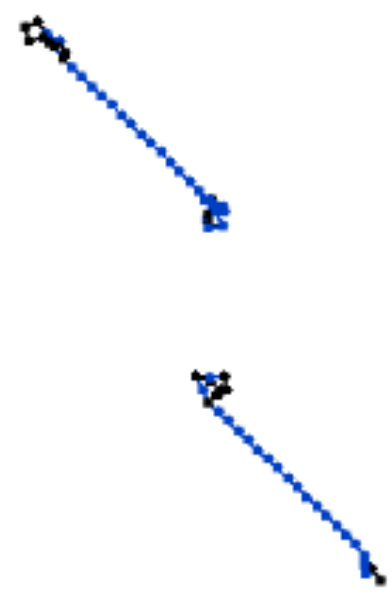

Fig. 22 Crack propagation for the geometry 2a-45-45 for FROCK normal stress-dependent criterion, $\sigma_{\theta}=-18.1 \mathrm{MPa}, \mathrm{c}=29.5 \mathrm{MPa}, \mathrm{r}_{0}=0.035 \mathrm{~cm}, \mu=0.70, \mathrm{~L} / \mathrm{r}_{0}=1.0, \varphi=0^{\mathrm{o}}$

The crack propagation and coalescence were never modeled acceptably using the ratio $\mathrm{L} / \mathrm{r}_{0}=1.0$. As can be seen by comparing Fig. 22 with Fig. 6b, a very odd crack pattern is obtained, in which neither wing cracks nor shear cracks obtained in the tests could be modeled.

The results obtained with the stress-dependent criterion for the geometry 2a-45-45 and ratio $\mathrm{L} / \mathrm{r}_{0}=2.0$ and 2.5 were very satisfactory, as can be seen by comparing Fig. 23 with Fig. 6b. As can be seen, both tensile and shear cracks initiate and propagate in a very acceptable fashion, leading to a coalescence similar to the one obtained in the tests.

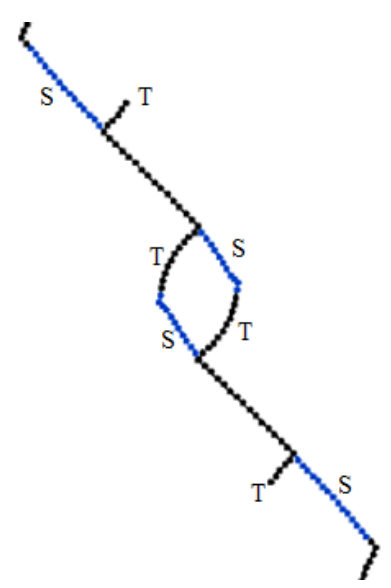

Fig. 23 Crack propagation for the geometry 2a-45-45 for FROCK normal stress-dependent criterion, $\sigma_{\theta}=-18.1 \mathrm{MPa}, \mathrm{c}=29.5 \mathrm{MPa}, \mathrm{r}_{0}=0.035 \mathrm{~cm}, \mathrm{~L} / \mathrm{r}_{0}=2.0$ and $2.5, \varphi=0^{\circ}$, showing tensile cracks "T" and shear cracks " $\mathrm{S}$ " 
The fact that good results were only obtained for a ratio $2.0<\mathrm{L} / \mathrm{r}_{0}<2.5$ may be due to two main reasons, one computational and one physical:

- First, it may be possible that outside of the 2.0-2.5 range, numerical convergence becomes more difficult and consequently the quality of the results decreases. Intuitively, varying $\mathrm{L} / \mathrm{r}_{0}$ in FROCK should have an analogous effect on the crack path to changing the mesh size in a Finite Element or Extended Finite Element code. In this case, a smaller $\mathrm{L} / \mathrm{r}_{0}$ seems to lead to a non-convergent solution in FROCK, while some initial investigations show that a larger $\mathrm{L} / \mathrm{r}_{0}$ leads to a rougher crack path. While in this study the optimal $\mathrm{L} / \mathrm{r}_{0}$ range was obtained by back-fitting the fracturing patterns in molded gypsum specimens, other rocks with different cracking patterns were not yet modeled in FROCK. Therefore, it can not be stated with certainty if the optimal $\mathrm{L} / \mathrm{r}_{0}$ is only computationdependent, or if it may also be material-dependent;

- Second, the $\mathrm{L} / \mathrm{r}_{0}$ may be able to capture the observed process of microcracking away from the crack tip and in a location where a future crack will develop (Fig. 24a). This phenomenon was clearly shown in the white-pacthing observed in marble by Wong (2008) and Brooks (2010), and in granite by Miller (2008) and Morgan (2013). Figure 24b illustrates this phenomenon in marble. While it is not believed that FROCK can detect a microcracking length $L$ that leads to a future crack, the best results obtained with some $\mathrm{L} / \mathrm{r}_{0}$ ratios may indicate there is an optimal relation between the microcracking length $\mathrm{L}$ and the plastic radius $\mathrm{r}_{0}$ which may be material-dependent. 


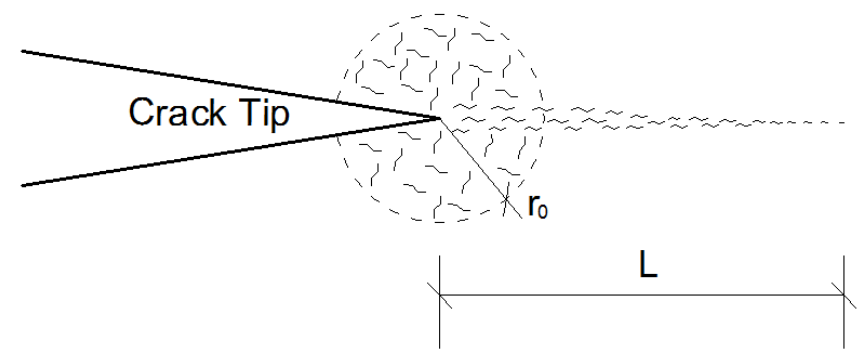

a)

Fig. 24 a) Micro-cracking length $L$ and plastic radius $r_{0}$ b) White-patching in marble subjected to uniaxial compression (from Wong, 2009)

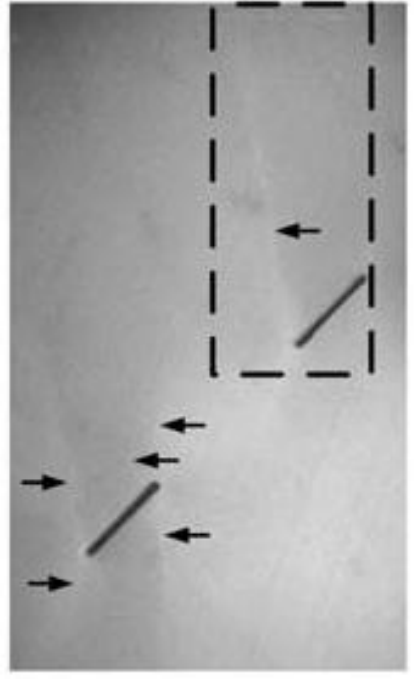

b)

\section{Summary and conclusions}

Study of stress-, strain- and energy criteria using ABAQUS

Based on the qualitative evaluations in section 3 , the stress and strain-based approaches seem to yield much better predictions than the energy approaches. The stress and strain-based criteria presented here have the great advantage of separating the tensile from the shear behavior. This separation cannot be done easily with the energy criteria studied, since there are usually three terms involved in the calculation of the energy. In the cases where only one energy term was studied, not all types of cracks predicted numerically corresponded to what was observed experimentally.

\section{Proposed strain-based criterion}

The proposed strain-based criterion appears to model quasi-static crack initiation and propagation better than Bobet's stress-based criterion. In fact, the cracking pattern results obtained in the study of five double-flaw stepped and coplanar geometries were better for the strain-based criterion than for the stress-based criterion. Specifically, the proposed strain-based criterion was capable of reasonably modeling two out of three coplanar double-flaw geometries, while these geometries could not be adequately modeled with the stress-based criterion. 


\section{Proposed normal stress-dependent criterion}

Poor crack initiation and propagation patterns were obtained as the friction angle $\varphi$ was increased. This suggests that a valid failure criterion might not depend on the friction angle. It was shown that as $\varphi$, i.e. the friction angle used to model the envelope of the failure criterion, increases the crack propagation pattern becomes less consistent with the experimental results, mainly evidenced by an odd shear crack propagation. This result indicates that for the microscale case, the critical shear stress at which a given material - particularly rock - fails does not depend upon the normal stress applied.

\section{Influence of the $L / r_{0}$ ratio in the modeled cracking processes}

Good results were never achieved for $\mathrm{L} / \mathrm{r}_{0}=1.0$, but were obtained for $2.0<\mathrm{L} / \mathrm{r}_{0}$ $<2.5$. This indicates that there is an optimum value of $\mathrm{L} / \mathrm{r}_{0}$ for which the results obtained are the best. This may be due to numerical convergence, or may indicate that there is a relation between a possible micro-cracking length $\mathrm{L}$, observed as white-patching in some rocks, and the plastic radius $\mathrm{r}_{0}$.

One can therefore conclude that this study led to improvements of the quasi-static crack initiation, -propagation and -coalescence model used in FROCK. This was achieved through the use of a strain-based criterion and a better consideration of the plastic zone radius $r_{0}$, which is one of FROCK's input parameters. Since this paper compared results obtained for molded gypsum, it is suggested that the improvements in FROCK's crack initiation, -propagation and -coalescence model be, eventually, further validated for other materials.

\section{REFERENCES}

Agwai, A et al. (2011) Predicting crack propagation with peridynamics: a comparative study. International Journal of Fracture 171:65- 78

Bobet A (1997) Fracture Coalescence in Rock Materials: Experimental Observations and Numerical Predictions. Sc. D. Thesis, Massachusetts Institute of Technology

Bobet A and Einstein HH (1998a) Numerical modeling of fracture coalescence in a model rock material. International Journal of Fracture, 92:221-252.

Bobet A and Einstein HH (1998b) Fracture coalescence in rock-type materials under uniaxial and biaxial compression. International Journal of Rock Mechanics and Mining Sciences, 35(7):863888.

Bobet A (2000) The initiation of secondary cracks in compression. Engineering Fracture Mechanics 66:187-219 
Brooks, $\mathrm{Z}$ et al. (2010) A nanomechanical investigation of the crack tip process zone. Proceedings of the $44^{\text {th }}$ U.S. Rock Mechanics and Geomechanics Symposium, Chicago, Paper 10-301

Chan M (1986) Automatic Two-Dimensional Multi-Fracture Propagation Modeling of Brittle Solids with Particular Application to Rock. Ph.D. Thesis, Massachusetts Institute of Technology

Chan M (1989) Hybridized displacement discontinuity and indirect boundary element method to model fracture propagation. International Journal of Fracture 45:263- 282

Erdogan F and Sih GC (1963) On the crack extension in plates under plane loading and transverse shear. Journal of Basic Engineering 85:305-321

Fagerström, M and Larsson, R (2008) Approaches to dynamic fracture modelling at finite deformations. Journal of the Mechanics and Physic of Solids 56:613-639

Gonçalves da Silva B (2009) Modeling of crack initiation, propagation and coalescence in rocks. S.M. Thesis, Massachusetts Institute of Technology

Gonçalves da Silva B and Einstein HH (2012) Study of stress and strain fields around a flaw tip in rock. Proceedings of the $46^{\text {th }}$ U.S. Rock Mechanics and Geomechanics Symposium, Chicago, Paper 12-593, 2074-2089

Guo ZK and Kobayashi AS (1995) Dynamic mixed mode fracture of concrete. International Journal of Solids and Structures, 32:2591-2607.

Ingraffea AR and Heuze FE (1980) Finite Element Models for Rock Fracture Mechanics. International Journal for Numerical and Analytical Methods in Geomechanics 4:25-43

Isaksson P and Ståhle P (2002) Prediction of shear crack growth direction under compressive loading and plane strain conditions. International Journal of Fracture 113:175-194

Kobayashi, AS (1999) Hybrid method in elastic and elastoplastic fracture mechanics. Optics and Lasers in Engineering 32:299-323

Liu, ZL (2011) An XFEM/Spectral element method for dynamic crack propagation. International Journal of Fracture 169:183-198

Martinez AR (1999) Fracture Coalescence in Natural Rock. MSc Thesis, Massachusetts Institute of Technology

Miller JT (2008) Crack coalescence in granite, S.M. Thesis, Massachusetts Institute of Technology

Morgan, S et al. (2013) Cracking processes in Barre granite: fracture process zones and crack coalescence. International Journal of Fracture 180:177-204

Ramulu, M and Kobayashi, AS (1985) Mechanics of crack curving and branching - a dynamic fracture analysis. International Journal of Fracture 27:187-201

Ravi-Chandar, K and Knauss, WG (1984) An experimental investigation into dynamic fracture: II. Microstructural aspects. International Journal of Fracture 26:65-80

Reyes O (1991) Experimental Study and Analytical Modeling of Compressive Fracture in Brittle Materials. Ph.D. Thesis, Massachusetts Institute of Technology.

Rice JR (1968) A Path Independent Integral and the Approximate Analysis of strain Concentration by Notches and Cracks. Journal of Applied Mechanics 35:379-386

Shen B and Stephansson O (1993) Numerical analysis of mixed mode I and mode II fracture propagation. International Journal of Rock Mechanics and Mining Sciences \& Geomechanics. 30(7):861-867 
Sih GC (1974) Strain-energy-density factory applied to mixed mode crack problems. International Journal of Fracture 10(3):305-321

Silling SA, Askari, E (2005) A meshfree method based on the peridynamic model of solid mechanics. Computers and Structures 83(17-18):1526- 1535

Vásárhelyi B and Bobet A (2000) Modeling of crack initiation, propagation and coalescence in uniaxial compression. Rock Mechanics and Rock Engineering 33(2):119-139

Wong NY (2008) Crack Coalescence in Molded Gypsum and Carrara Marble. Ph.D. Thesis, Massachusetts Institute of Technology

Wong LNY and Einstein HH (2009a) Crack coalescence in molded gypsum and Carrara marble: Part 1 - Macroscopic observations and interpretation. Rock Mechanics and Rock Engineering 42(3):475-511

Wong LNY and Einstein HH (2009b) Crack coalescence in molded gypsum and Carrara marble: Part 2 - Microscopic observations and interpretation. Rock Mechanics and Rock Engineering 42(3):513-545

Xu, Y. and Yuan, H. (2011) Applications of normal stress dominated cohesive zone models for mixed-mode crack simulation based on the extended finite element methods. Engineering Fracture Mechanics 78:544-558

$\mathrm{Yu}, \mathrm{C}$ and Kobayashi, A (1994) Fracture process zone associated with mixed mode fracture of $\mathrm{SiC}_{\mathrm{W}} / \mathrm{Al}_{2} \mathrm{O}_{3}$. Journal of Non-Crystalline Solids 177:26-35 